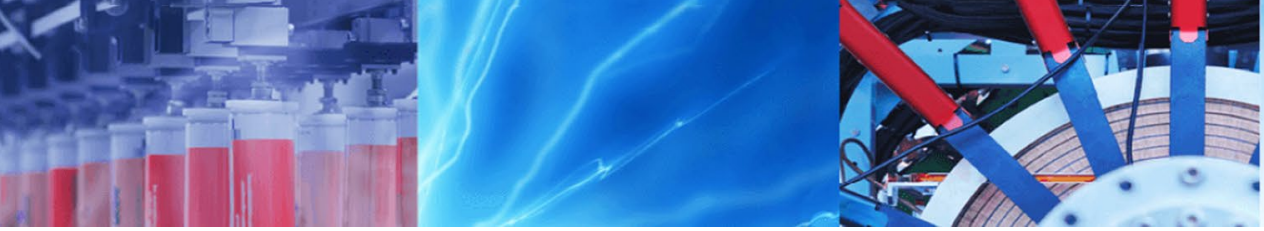

Research Article

\title{
Photocatalytic activity of $\mathrm{Gd}_{2} \mathrm{O}_{2} \mathrm{CO}_{3} \cdot \mathrm{ZnO} \cdot \mathrm{CuO}$ nanocomposite used for the degradation of phenanthrene
}

\author{
Nthambeleni Mukwevho ${ }^{1}$ - Elvis Fosso-Kankeu ${ }^{1}$ (D) - Frans Waanders ${ }^{1} \cdot$ Neeraj Kumar $^{2}$ - Suprakas Sinha Ray ${ }^{2,3}$. \\ Xavier Yangkou Mbianda ${ }^{3}$
}

(c) Springer Nature Switzerland AG 2018

\begin{abstract}
Multimetal oxides nanocomposite photocatalysts based on $\mathrm{Gd}_{2} \mathrm{O}_{2} \mathrm{CO}_{3} \cdot \mathrm{ZnO} \cdot \mathrm{CuO}$ were prepared by a co-precipitation method and carefully characterized using a range of analytical techniques. More specifically, analysis by X-ray diffraction and electron microscopies confirmed the identity and quality of the as-synthesized powders. The photocatalytic degradation activities of these nanocomposites towards phenanthrene were then investigated by measuring the effects of catalyst dosage, irradiation time, and oxidant addition. In addition, the pseudo first-order kinetic model was used to determine the rate constant of the degradation reaction. Optimum dosages of $0.6,0.6$, and $0.4 \mathrm{gL}^{-1}$ were recorded when using $\mathrm{CuO}, \mathrm{Cu}-\mathrm{CuO} / \mathrm{ZnO}$, and $\mathrm{Gd}_{2} \mathrm{O}_{2} \mathrm{CO}_{3} \cdot \mathrm{ZnO} \cdot \mathrm{CuO}$, respectively. In addition, the $\mathrm{Gd}_{2} \mathrm{O}_{2} \mathrm{CO}_{3} \cdot \mathrm{ZnO} \cdot \mathrm{CuO}$ composite exhibited a higher removal efficiency than both $\mathrm{Cu}-\mathrm{CuO} / \mathrm{ZnO}$ and the pure $\mathrm{CuO}$ nanoparticles. Furthermore, the addition of oxidants influenced the removal of phenanthrene from solution. Finally, the photocatalytic degradation data followed pseudo first-order kinetics as defined by the Langmuir-Hinshelwood model, which allowed prediction of the faster degradation rate by the $\mathrm{Gd}_{2} \mathrm{O}_{2} \mathrm{CO}_{3} \cdot \mathrm{ZnO} \cdot \mathrm{CuO}$ nanocomposite. The newly synthesized nanocomposite could therefore be considered for the removal of phenanthrene and related polycyclic aromatic hydrocarbons from contaminated water.
\end{abstract}

Keywords Metal oxide $\cdot$ Nanocomposite $\cdot$ Photocatalytic degradation $\cdot$ Kinetic model $\cdot$ Polycyclic aromatic hydrocarbons

\section{Introduction}

Water pollution is currently a major problem worldwide partly due to the discharge of various contaminants into rivers, examples of such contaminants include the polycyclic aromatic hydrocarbons (PAHs), dyes, and toxic inorganic ions [1-4]. PAHs are common components in the coal, petroleum, and oil industries $[5,6]$. One such PAHs is phenanthrene, which is also found in cigarettes and has been reported to lead to cardiovascular disease $[7,8]$. Although several techniques have been employed for the removal of organic pollutants from wastewater, complete removal has yet to be achieved [9-12]. In addition, a number of these techniques are undesirable, as they create sludge by-products and require a significant energy input to maintain high pressures [13-15]. However, photocatalytic degradation is a promising technique for the removal of PAHs because of its low cost, fast degradation rate, and

Electronic supplementary material The online version of this article (https://doi.org/10.1007/s42452-018-0012-0) contains supplementary material, which is available to authorized users.

$\triangle$ Elvis Fosso-Kankeu, kaelpfr@yahoo.fr; elvisfosso.ef@gmail.com; Elvis.FossoKankeu@nwu.ac.za|'ater Pollution Monitoring and Remediation Initiatives Research Group, School of Chemical and Minerals Engineering, North West University, P. Bag X6001, Potchefstroom 2520, South Africa. ${ }^{2}$ DST-CSIR National Centre for Nanostructured Materials, Council for Scientific and Industrial Research, Pretoria 0001, South Africa. ${ }^{3}$ Department of Applied Chemistry, University of Johannesburg, Doornfontein, Johannesburg 2028, South Africa. 
environmental friendliness [16]. As such, the potential of photocatalytic degradation to remove phenanthrene from aqueous solution will be investigated in this study. For this purpose, $\mathrm{ZnO}$ will be considered as the parental photocatalyst, due to its high chemical stability, low cost, and its relatively high quantum efficiency [17]. However, metal oxides such as $\mathrm{ZnO}$ are active only in the ultraviolet region and exhibit a moderate performance. As such, the development of novel materials with reduced band gap energies has been investigated to increase the response to the abundant visible light photons $[18,19]$. For example, $\mathrm{CuO}$ is a chemically stable p-type metal oxide with a band energy gap of 1.2-1.8 eV [20, 21]. As such, metallic $\mathrm{Cu}, \mathrm{CuO}$, and the corresponding complexes are well-established catalysts for the transformation of various chemicals into valuable products [22-24]. Due to its low energy band gap, $\mathrm{CuO}$ is often employed as a co-catalyst in combination with large band gap energy catalysts such as $\mathrm{TiO}_{2}$ and $\mathrm{ZnO}$ to increase the photocatalytic rate under visible light [25]. Indeed, $\mathrm{ZnO} / \mathrm{CuO}$ composites have been reported to exhibit improved charge carrier separation and a decreased rate of recombination, which in turn improves the photodegradation efficiency [26]. It has been reported that the formation of $p-n$ heterocoupling at the $\mathrm{CuO} / \mathrm{ZnO}$ interface can lead to superior charge separation and thus an increased photocatalytic activity [27]. Furthermore, the photocatalytic activity of $\mathrm{CuO} / \mathrm{ZnO}$ can be increased by the introduction of Cu nanoparticles (NPs) on the surface. To the best of our knowledge, the photocatalytic activity of the $\mathrm{Cu}-\mathrm{CuO} / \mathrm{ZnO}$ composite for the degradation of phenanthrene has not yet been investigated. The amendment of the physicochemical properties of semiconductors through doping and heterostructures with rare earth metal/metal oxide for the improvement of their photocatalytic activities have been previously reported [28, 29]; it is suggested that the increased photocatalytic activities of gadolinium incorporated semiconductor is mainly due to the interfacial charge transfer of its $4 \mathrm{f}$ shells and the elimination of electron-hole recombination. Hence, the nanocomposite (NC) of $\mathrm{CuO} / \mathrm{ZnO}$ with gadolinium was considered for improved photodegradation of phenanthrene in water.

Thus, we herein report the synthesis of $\mathrm{CuO}, \mathrm{Cu}-\mathrm{CuO} /$ $\mathrm{ZnO}$ nanocomposite (NC), and $\mathrm{Gd}_{2} \mathrm{O}_{2} \mathrm{CO}_{3} \cdot \mathrm{ZnO} \cdot \mathrm{CuO} \mathrm{NC}$, followed by comparison of their photocatalytic activities towards phenanthrene photodegradation. The obtained products will then be characterized using a range of techniques, including Fourier transform infrared (FTIR) spectroscopy, ultraviolet-visible (UV-vis) spectroscopy, scanning electron microscopy (SEM), Transmission electron microscopy (TEM) and X-ray diffraction (XRD). The kinetics of the photocatalytic activity will be studied by measuring the removal rates of different photocatalysts. Therefore, the objectives of this work are to synthesize multimetal oxide heterocatalysts to improve the excitability of $\mathrm{ZnO}$ and $\mathrm{CuO}$ under visible light, and enhance the charge carrier mobility for the degradation of phenanthrene.

\section{Experimental Section}

\subsection{Materials}

Copper nitrate trihydrate ( $>99 \%)$, zinc acetate dihydrate $(\geq 98 \%)$, copper acetate ( $98 \%)$, gadolinium nitrate hexahydrate (99.9\% trace metals basis), and phenanthrene (98\%) were obtained from Sigma-Aldrich, South Africa and used directly without any further purification.

\subsection{Preparation of $\mathrm{CuO}, \mathrm{ZnO} / \mathrm{CuO}$, and $\mathrm{Gd}_{2} \mathrm{O}_{2} \mathrm{CO}_{3} \cdot \mathrm{ZnO} \cdot \mathrm{CuO}$}

Copper oxide nanoparticles (CuO NPs) were prepared using an environmentally friendly synthetic method based on the use of banana peel as a natural source serving as structure-controlling agent. More specifically, a sample of ripe banana peel $(20 \mathrm{~g})$ was weighed and washed with ethanol. The banana peel was then cut into pieces of $2 \mathrm{~mm}^{2}$, added to distilled water $(40 \mathrm{~mL})$, and heated at $80^{\circ} \mathrm{C}$ for $15 \mathrm{~min}$. Following filtration, a portion of the resulting extract $(30 \mathrm{~mL})$ was added to a reaction vessel and heated at $80^{\circ} \mathrm{C}$ with constant stirring. Copper nitrate trihydrate $(1 \mathrm{~g})$ was added to this hot banana peel extract. This mixture was refluxed and the resulting precipitate was transferred to a crucible and heated in a furnace at $400{ }^{\circ} \mathrm{C}$ for $3 \mathrm{~h}$ to yield a black powder. For synthesis of the $\mathrm{Cu}-\mathrm{CuO} / \mathrm{ZnO} \mathrm{NC}$, the desired quantities of zinc acetate dihydrate and copper acetate (1:1 ratio) were mixed and ground using mortar pestle. The obtained powder was transferred to an alumina crucible and annealed at $350^{\circ} \mathrm{C}$ for $3 \mathrm{~h}$ under air in a muffle furnace. The multimetal oxide $\left(\mathrm{Gd}_{2} \mathrm{O}_{2} \mathrm{CO}_{3} \cdot \mathrm{ZnO} \cdot \mathrm{CuO}\right)$ composite was prepared via a coprecipitation method similar to that reported by Subhan et al. [30], with the exception that gadolinium nitrate hexahydrate was used instead of lanthanum nitrate.

\subsection{Characterization}

The morphology of the photocatalysts was examined by SEM (VEGA SEM, TESCAN), and the chemical compositions were determined by $\mathrm{X}$-ray energy dispersive spectroscopy (EDS) coupled with SEM. The interior characterization of composite was performed using a high resolution transmission electron microscope (HRTEM, JEOL JEM-2100, $200 \mathrm{kV}$ ). XRD data for the prepared samples were recorded using a Philips PANalytical X'Pert PRO PW 3040/60 X-ray 
diffractometer with $\mathrm{Cu}-\mathrm{Ka}$ radiation $(\lambda=0.15418 \mathrm{~nm})$. UV-vis absorbance spectra were recorded using a Shimadzu UV-2401PC spectrophotometer. FTIR spectra were recorded on a Perkin Elmer Spectrum 100 FTIR spectrophotometer.

\subsection{Evaluation of the photocatalytic activities of the prepared photocatalysts}

The photocatalytic degradation of phenanthrene was investigated in a photocatalytic chamber using the prepared photocatalysts (i.e., $\mathrm{CuO}, \mathrm{ZnO} / \mathrm{CuO}$, and $\left.\mathrm{Gd}_{2} \mathrm{O}_{2} \mathrm{CO}_{3} \cdot \mathrm{ZnO} \cdot \mathrm{CuO}\right)$. A UV filter was utilized to cut off wavelengths $<400 \mathrm{~nm}$. All experiments were performed by suspending the photocatalysts in the reactor containing a phenanthrene solution (20 ppm), and the reactions were carried out at $25^{\circ} \mathrm{C}$ in the photocatalytic chamber. After the desired time interval (20 min), the concentration of residual phenanthrene in each solution was measured by recording the absorbance intensity of the solution at a maximum absorbance-wavelength of $271 \mathrm{~nm}$. The phenanthrene photodegradation efficiency of each photocatalyst was then calculated using Eq. (1) [26]:

Photodegradation efficiency $(\%)=\frac{C_{0}-C_{t}}{C_{0}} \times 100$

where $C_{0}$ is the initial phenanthrene concentration and $C_{t}$ is the residual phenanthrene concentration in solution at time, $\mathrm{t}$.

\section{Results and discussion}

\subsection{Structural and morphological characterization}

Following preparation of the various photocatalysts, XRD measurements were carried out to determine the purities and crystal structures of the powdered $\mathrm{CuO}$ NPs, $\mathrm{Cu}-\mathrm{CuO} /$ $\mathrm{ZnO} \mathrm{NC}$, and $\mathrm{Gd}_{2} \mathrm{O}_{2} \mathrm{CO}_{3} \cdot \mathrm{ZnO} \cdot \mathrm{CuO} \mathrm{NC}$. As shown in Fig. 1, $\mathrm{CuO}$ gave sharp diffraction peaks at $32.35^{\circ}(110), 35.52^{\circ}$ $(-111), 38.75^{\circ}(111), 48.76^{\circ}(-202), 53.58^{\circ}(020), 58.29^{\circ}$ (202), $66.30^{\circ}(-113), 68.02^{\circ}(220), 72.35^{\circ}(311)$, and $75.19^{\circ}$

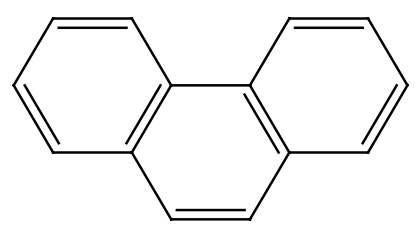

Fig. 1 Chemical structure of the polycyclic aromatic hydrocarbon, phenanthrene $\left(\mathrm{C}_{14} \mathrm{H}_{10}\right)$
(004), thereby indicating that this sample was composed of a pure crystalline monoclinic phase, due to its correlation with JCPDS Card No. 45-0937 [31].

As expected, the XRD pattern of $\mathrm{Cu}-\mathrm{CuO} / \mathrm{ZnO}$ contained peaks corresponding to $\mathrm{Cu}, \mathrm{CuO}$, and $\mathrm{ZnO}$ nanomaterials. More specifically, intense sharp peaks (as indicated by ${ }^{*}$ ) at $43.35^{\circ}(111), 50.49^{\circ}(200)$, and $74.08^{\circ}(220)$, suggest the formation of crystalline Cu NPs [32], while peaks at $31.76^{\circ}(100), 34.62^{\circ}(002), 36.53^{\circ}(101), 47.70^{\circ}$ (102), $56.85^{\circ}(110), 62.86^{\circ}(103), 66.67^{\circ}(200), 68.20^{\circ}(112)$, and $69.15^{\circ}$ (201) (as indicated by \#) were consistent with the hexagonal wurtzite structure of ZnO (JCPDS Card No. 89-1397) [11]. In this case, the presence of $\mathrm{ZnO}$ reduced the crystallinity of $\mathrm{CuO}$ in the $\mathrm{Cu}-\mathrm{CuO} / \mathrm{ZnO}$ composite. Furthermore, peaks corresponding to $\mathrm{ZnO}, \mathrm{CuO}$, and $\mathrm{Gd}_{2} \mathrm{O}_{2} \mathrm{CO}_{3}$ were observed in the $\mathrm{Gd}_{2} \mathrm{O}_{2} \mathrm{CO}_{3} \cdot \mathrm{ZnO} \cdot \mathrm{CuO} \mathrm{NC}$, as indicated by red, green, and black lines, respectively. As shown in Fig. 2, no additional phases were observed, and the diffraction pattern of $\mathrm{Gd}_{2} \mathrm{O}_{2} \mathrm{CO}_{3}$ in the $\mathrm{NC}$ corresponded with the literature $[30,33]$. It should also be noted that the crystallinity of a photocatalyst is of

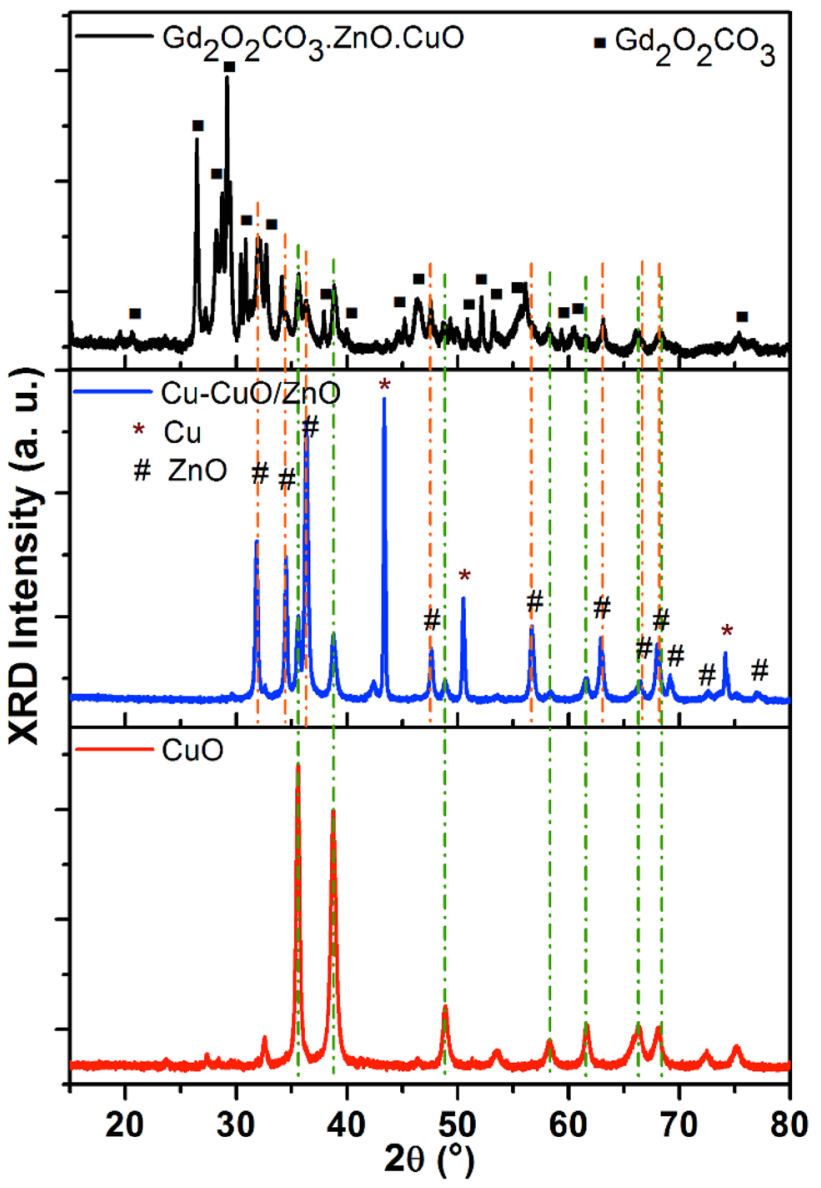

Fig. 2 XRD patterns of the $\mathrm{CuO} N P s, \mathrm{Cu}-\mathrm{CuO} / \mathrm{ZnO} \mathrm{NC}$, and $\mathrm{Gd}_{2} \mathrm{O}_{2} \mathrm{CO}_{3} \cdot \mathrm{ZnO} \cdot \mathrm{CuO} \mathrm{NC}$ 
particular importance, as the NC exhibiting the highest crystallinity is likely to exhibit a superior photocatalytic degradation activity.

The functional groups present in the prepared samples were then examined by FTIR and the results are presented in Fig. 3. More specifically, in the spectrum of $\mathrm{CuO}$, the transmittance peak observed at $602 \mathrm{~cm}^{-1}$ was attributed to the $\mathrm{Cu}-\mathrm{O}$ vibration, thereby confirming the synthesis of pure monoclinic CuO NPs. In addition, the peak centred at $3426 \mathrm{~cm}^{-1}$ corresponds to $-\mathrm{OH}$ stretching, while that at $2930 \mathrm{~cm}^{-1}$ could be attributed to the $-\mathrm{C}-\mathrm{H}$ stretching mode of the aliphatic chains. Peaks corresponding to $\mathrm{C}=\mathrm{C}$ stretching $\left(1599 \mathrm{~cm}^{-1}\right),-\mathrm{N}-\mathrm{H}$ bending $\left(1541 \mathrm{~cm}^{-1}\right),-\mathrm{C}-\mathrm{N}$ stretching $\left(1379 \mathrm{~cm}^{-1}\right)$, and $=\mathrm{C}-\mathrm{N}$ bending $\left(849 \mathrm{~cm}^{-1}\right)$ likely arose due to presence of residue from the banana peel extract (i.e., containing chlorophyll catabolites or other organic moieties bearing hydroxyl, amine, and conjugated groups) on the CuO NP surfaces [34]. In the case of the $\mathrm{Cu}-\mathrm{CuO} / \mathrm{ZnO} \mathrm{NC}$, the characteristic peaks of $\mathrm{CuO}$ shifted to lower wavenumbers and merged with that of the $\mathrm{Zn}-\mathrm{O}$ vibration. Moreover, in FTIR spectrum of $\mathrm{Gd}_{2} \mathrm{O}_{2} \mathrm{CO}_{3} \cdot \mathrm{ZnO} \cdot \mathrm{CuO} \mathrm{NC}$, the peak at $3420 \mathrm{~cm}^{-1}$ could be attributed to the $\mathrm{O}-\mathrm{H}$ stretching of water molecules, while the characteristics vibration bands at $1456,1055,991$, and $692 \mathrm{~cm}^{-1}$ are related to the asymmetric $v_{3} \mathrm{CO}_{3}$, symmetric $v_{1} \mathrm{CO}_{3}$, asymmetric $v_{2} \mathrm{CO}_{3}$, and asymmetric $v_{4} \mathrm{CO}_{3}$ vibrations, respectively, thereby confirming the presence of the $\mathrm{CO}_{3}{ }^{2-}$ group [35]. Furthermore, peaks corresponding to the $\mathrm{Zn}-\mathrm{O}$ and $\mathrm{Cu}-\mathrm{O}$ vibrations may be shifted to lower wavenumbers due to the presence of multimetal oxides.

The absorption coefficient is also an important parameter in determining the penetration of light waves into photocatalysts. As such, the light absorption behaviour

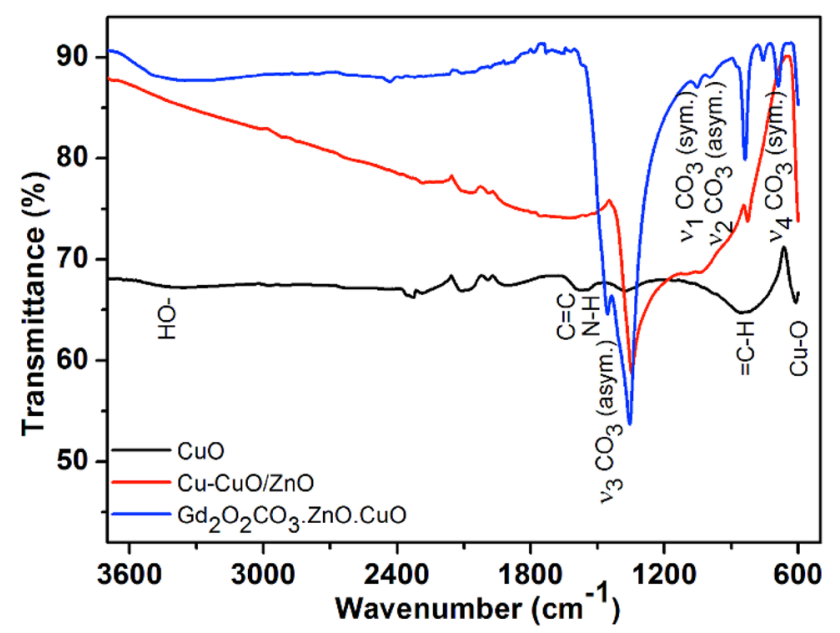

Fig. 3 FTIR spectra of the $\mathrm{CuO} \mathrm{NPs}, \mathrm{Cu}-\mathrm{CuO} / \mathrm{ZnO} \mathrm{NC}$, and $\mathrm{Gd}_{2} \mathrm{O}_{2} \mathrm{CO}_{3} \cdot \mathrm{ZnO} \cdot \mathrm{CuO} \mathrm{NC}$ with corresponding assigned vibrational signatures of each prepared photocatalyst was monitored by UV-vis spectroscopy, as shown in Fig. $4 a-c$. In the case of the $\mathrm{Cu}-\mathrm{CuO} / \mathrm{ZnO}$ composite, two strong absorption bands were observed in the visible region at 378 and $314 \mathrm{~nm}$, while pure $\mathrm{CuO}$ exhibited an absorbance peak at $313 \mathrm{~nm}$. For the $\mathrm{Gd}_{2} \mathrm{O}_{2} \mathrm{CO}_{3} \cdot \mathrm{ZnO} \cdot \mathrm{CuO} \mathrm{NC}$, the absorbance peaks exhibited a red shift, indicating modification of the electronic structures due to the presence of multimetal oxides (see the inset of Fig. 4c). In addition, a good absorption capacity was exhibited by the $\mathrm{Gd}_{2} \mathrm{O}_{2} \mathrm{CO}_{3} \cdot \mathrm{ZnO} \cdot \mathrm{CuO} \mathrm{NC}$ over a wide range of the spectrum. The optical energy band gaps of the prepared samples were then determined based on a Tauc plot of $(a h v)^{2}$ versus the photon energy, considering direct allowed transition [21,36]. As a result, band gaps of 2.41,2.63, and $2.84 \mathrm{eV}$ were determined for $\mathrm{CuO}, \mathrm{Cu}-\mathrm{CuO} / \mathrm{ZnO}$, and $\mathrm{Gd}_{2} \mathrm{O}_{2} \mathrm{CO}_{3} \cdot \mathrm{ZnO} \cdot \mathrm{CuO}$, respectively (Fig. $4 a-d)$. Compared to the bulk band gap of $\mathrm{CuO}$ (i.e., 1.2-1.3 eV), the obtained band gap for the CuO NPs was high, possibly due to the quantum confinement effect. Furthermore, it can be concluded that all prepared samples are indeed visible light photocatalysts, due to their low band gap energies.

The morphologies of the prepared photocatalysts were then investigated by SEM. As shown in Fig. 5a, conical particles composed of smaller (i.e., $<100 \mathrm{~nm}$ ) CuO NPs were observed. This is expected to result from the presence of residual functional groups (i.e., hydroxyl, amine, and conjugated carbons) from the banana peel extract $[15,34,37]$, which direct the growth of CuO NPs. However, the $\mathrm{Cu}-\mathrm{CuO} / \mathrm{ZnO} \mathrm{NC}$ exhibited diverse morphologies, namely spherical NPs, nanorods, and nanocubes (as shown in Fig. 5b-d). Furthermore, EDS mapping of the $\mathrm{Cu}-\mathrm{CuO} / \mathrm{ZnO} \mathrm{NC}$ was performed to identify these nanostructures (see Fig. S1, Supplementary Information). Upon careful inspection, it was observed that the small NPs ( $30 \mathrm{~nm})$, decorated nanorods, and nanocubes originated from $\mathrm{Cu}$ to $\mathrm{CuO}$. In addition, the $\mathrm{ZnO}$ NPs exhibit irregular shapes measuring between 5 and $150 \mathrm{~nm}$. Various morphologies of $\mathrm{Cu}-\mathrm{CuO} / \mathrm{ZnO}$ were also formed as the generated nuclei were surrounded by $\mathrm{CH}_{3} \mathrm{COO}^{-}$ions. This was followed by further structural evolution upon decomposition of the $\mathrm{CH}_{3} \mathrm{COO}^{-}$ions to give $\mathrm{CO}_{2}$ [11]. It can also be observed that $\mathrm{ZnO}$ NPs grow on the surface of the $\mathrm{Cu}-\mathrm{CuO}$ rods. Moreover, as shown in Fig. $5 \mathrm{e}-\mathrm{f}$, the multimetal oxide $\mathrm{NC}$ (i.e., $\mathrm{Gd}_{2} \mathrm{O}_{2} \mathrm{CO}_{3} \cdot \mathrm{ZnO} \cdot \mathrm{CuO}$ ) produced nanometric particles of various sizes. Based on these observations, the various metal oxides present in the NCs are indicated in Fig. 5f. EDX mapping was also employed to determine the elemental distribution within the composite, with Fig. S2 (Supplementary Information) showing the distributions of $\mathrm{C}, \mathrm{O}, \mathrm{Zn}, \mathrm{Cu}$, and $\mathrm{Gd}$ in the prepared $\mathrm{Gd}_{2} \mathrm{O}_{2} \mathrm{CO}_{3} \cdot \mathrm{ZnO} \cdot \mathrm{CuO} \mathrm{NC}$. More specifically, $\mathrm{Cu}$, $\mathrm{Zn}$, and $\mathrm{Gd}$ were dispersed uniformly, confirming that 

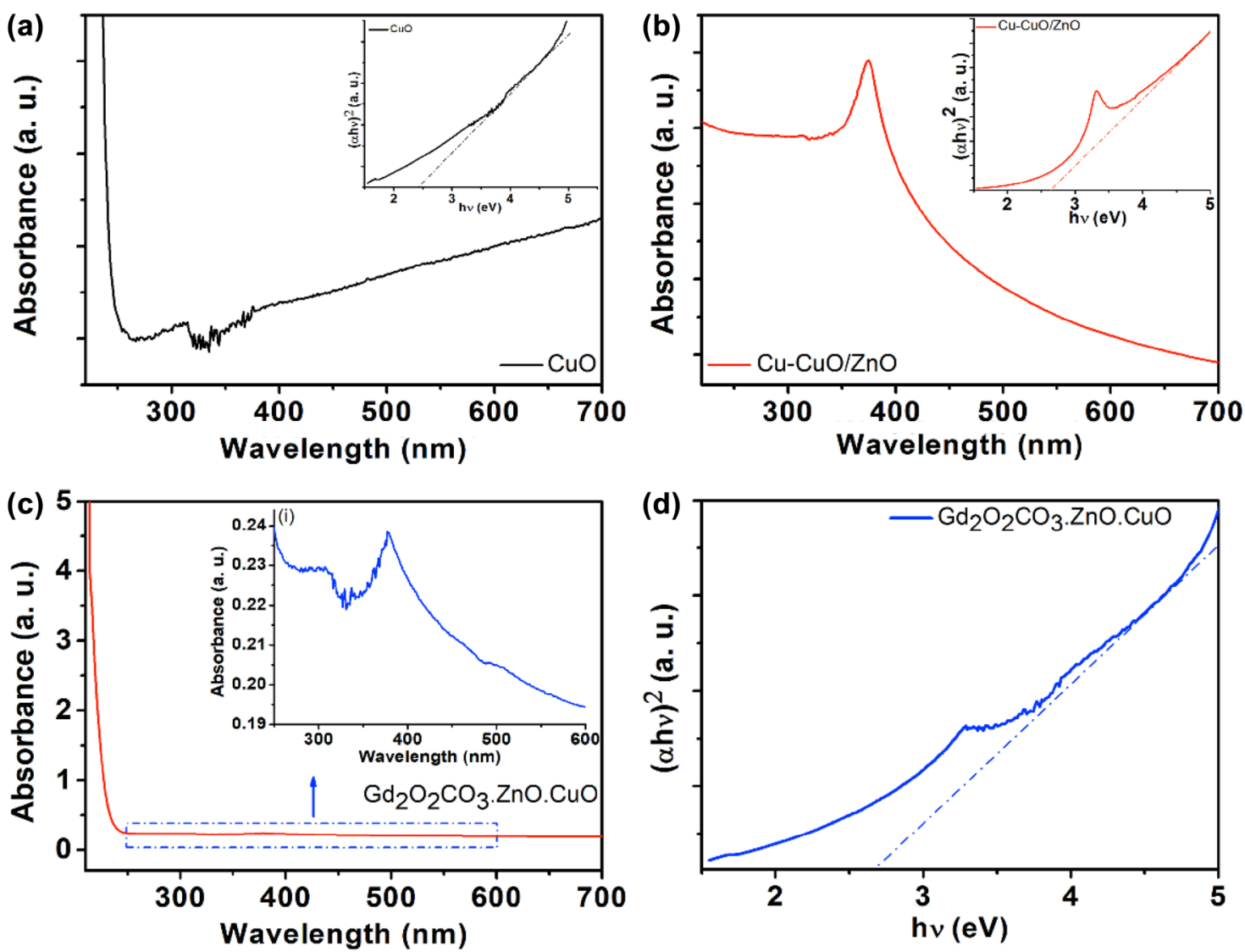

Fig. 4 UV-vis absorption spectra of a CuO NPs, and $\mathbf{b} \mathrm{Cu}-\mathrm{CuO} / \mathrm{ZnO} \mathrm{NC}$. The insets show Tauc plots for estimation of the direct band gaps. $\mathbf{c}$ UV-vis absorption spectrum of $\mathrm{Gd}_{2} \mathrm{O}_{2} \mathrm{CO}_{3} \cdot \mathrm{ZnO} \cdot \mathrm{CuO}$ NC. $\mathbf{d}$ Tauc plot for estimation of the direct band gap of $\mathrm{Gd}_{2} \mathrm{O}_{2} \mathrm{CO}_{3} \cdot \mathrm{ZnO} \cdot \mathrm{CuO} \mathrm{NC}$

the prepared $\mathrm{Gd}_{2} \mathrm{O}_{2} \mathrm{CO}_{3} \cdot \mathrm{ZnO} \cdot \mathrm{CuO}$ composite has a high purity. The above results therefore confirm the successful formation of $\mathrm{CuO} N \mathrm{NP}$, the $\mathrm{Cu}-\mathrm{CuO} / \mathrm{ZnO} \mathrm{NC}$, and the $\mathrm{Gd}_{2} \mathrm{O}_{2} \mathrm{CO}_{3} \cdot \mathrm{ZnO} \cdot \mathrm{CuO} \mathrm{NC}$. Furthermore, interior characterization of as-synthesized nanocomposite was executed by TEM and HRTEM. Figure 6a displays the low magnification TEM image of $\mathrm{Gd}_{2} \mathrm{O}_{2} \mathrm{CO}_{3} \cdot \mathrm{ZnO} \cdot \mathrm{CuO} \mathrm{NC}$ and it has shown the various shapes nanoparticles from small to high aspect ratio possibly belonging to $\mathrm{ZnO}, \mathrm{Cu}, \mathrm{CuO}$, and $\mathrm{Gd}_{2} \mathrm{O}_{2} \mathrm{CO}_{3}$ NPs. Similar morphologies of NPs were noticed in SEM images of composite. The HRTEM image clearly demonstrated the presence of $\mathrm{CuO} \mathrm{ZnO}$, and $\mathrm{Gd}_{2} \mathrm{O}_{2} \mathrm{CO}_{3} \mathrm{NPs}$ in the composite (Fig. $6 \mathrm{~b}-\mathrm{C}$ ). The lattice fringe with interplanar spacing (d) of 0.260 and $0.283 \mathrm{~nm}$ corresponds to the growth direction of [001] and [100] facet of $\mathrm{ZnO}$ crystals, respectively. The lattice fringe with d value of $0.226 \mathrm{~nm}$ corresponds to the growth direction of [111] facet of $\mathrm{CuO}$ crystals. In Fig. $6 \mathrm{c}$, the lattice fringe with d value of $0.302 \mathrm{~nm}$ matches to the growth direction of [102] facets of $\mathrm{Gd}_{2} \mathrm{O}_{2} \mathrm{CO}_{3}$ NPs. Based on the abovementioned observations, the desired $\mathrm{Gd}_{2} \mathrm{O}_{2} \mathrm{CO}_{3} \cdot \mathrm{ZnO} \cdot \mathrm{CuO} \mathrm{NC}$ was successfully formed. Furthermore, the Brunauer-Emmett-Teller (BET) surface area of $\mathrm{CuO}$ and NC was determined using nitrogen adsorption-desorption isotherms. As shown in Fig. S3, the specific surface areas of $\mathrm{CuONPs}, \mathrm{Cu}-\mathrm{CuO} / \mathrm{ZnO} \mathrm{NC}$ and $\mathrm{Gd}_{2} \mathrm{O}_{2} \mathrm{CO}_{3} \cdot \mathrm{ZnO} \cdot \mathrm{CuO} \mathrm{NC}$ were found to be $0.5956,4.2949$ and $10.7291 \mathrm{~m}^{2} \mathrm{~g}^{-1}$, respectively. The comparatively high surface area of $\mathrm{Gd}_{2} \mathrm{O}_{2} \mathrm{CO}_{3} \cdot \mathrm{ZnO} \cdot \mathrm{CuO} \mathrm{NC}$ is related to combination effects of $\mathrm{ZnO}$ and $\mathrm{CuO}$ NPs with $\mathrm{Gd}_{2} \mathrm{O}_{2} \mathrm{CO}_{3} \mathrm{NPs}$.

\subsection{Photocatalytic degradation of phenanthrene}

\subsubsection{Effect of photocatalyst loading}

We initially wished to examine the effect of the photocatalyst loading on the degradation of phenanthrene. To avoid the use of excess photocatalyst, the optimum dosage for the efficient degradation of phenanthrene must be determined $[38,39]$. We therefore investigated the effect of catalyst loading on the degradation of phenanthrene, using a $20 \mathrm{ppm}$ solution of phenanthrene $(100 \mathrm{~mL})$ at $\mathrm{pH} 4$ under visible light at room temperature for $3 \mathrm{~h}$ in the presence of $20-60 \mathrm{mg}$ of the desired photocatalyst. As shown in Fig. 7, the optimum dosages of $\mathrm{CuO}$ and the $\mathrm{ZnO} / \mathrm{CuO} \mathrm{NC}$ 
Fig. 5 SEM images of a $\mathrm{CuO}$ $\mathrm{NPs}$, b-d $\mathrm{Cu}-\mathrm{CuO} / \mathrm{ZnO} \mathrm{NC}$, and e-f $\mathrm{Gd}_{2} \mathrm{O}_{2} \mathrm{CO}_{3} \cdot \mathrm{ZnO} \cdot \mathrm{CuO} \mathrm{NC}$

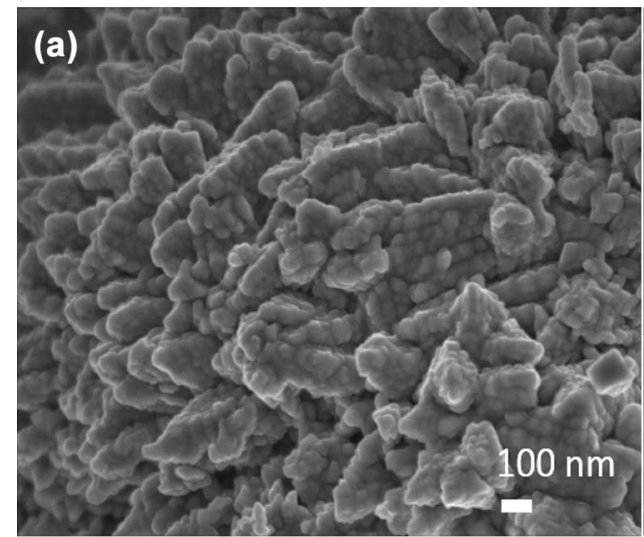

(b)

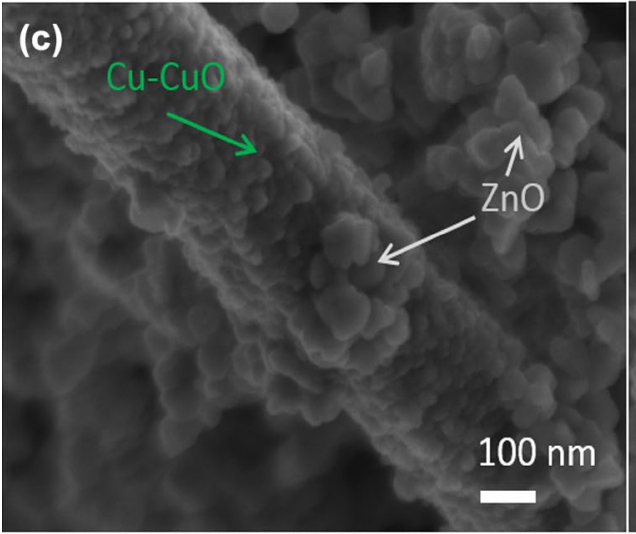

(d)
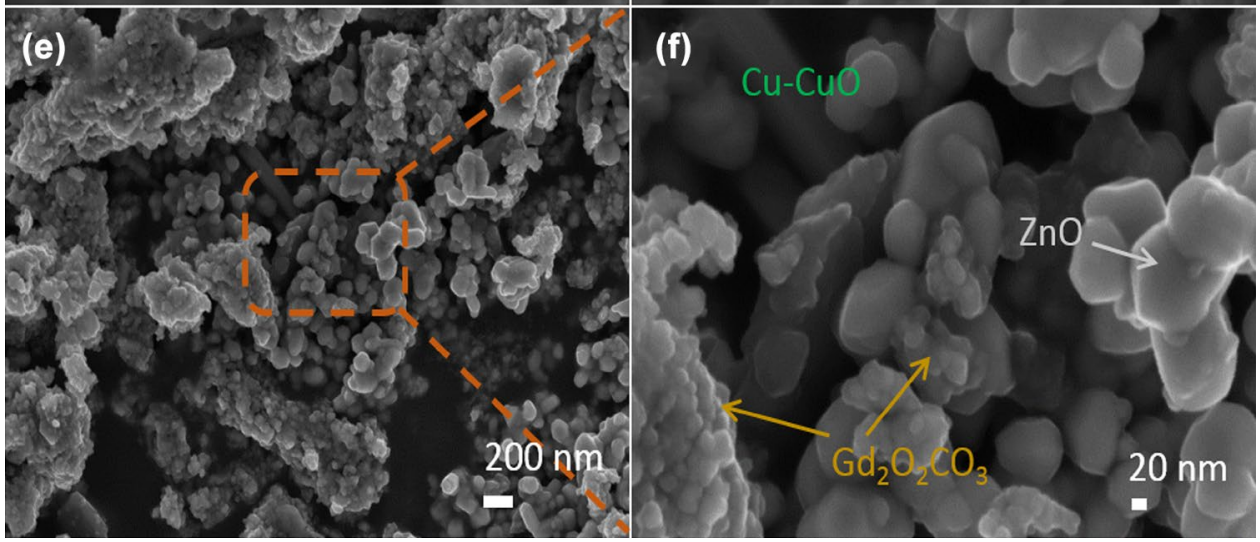
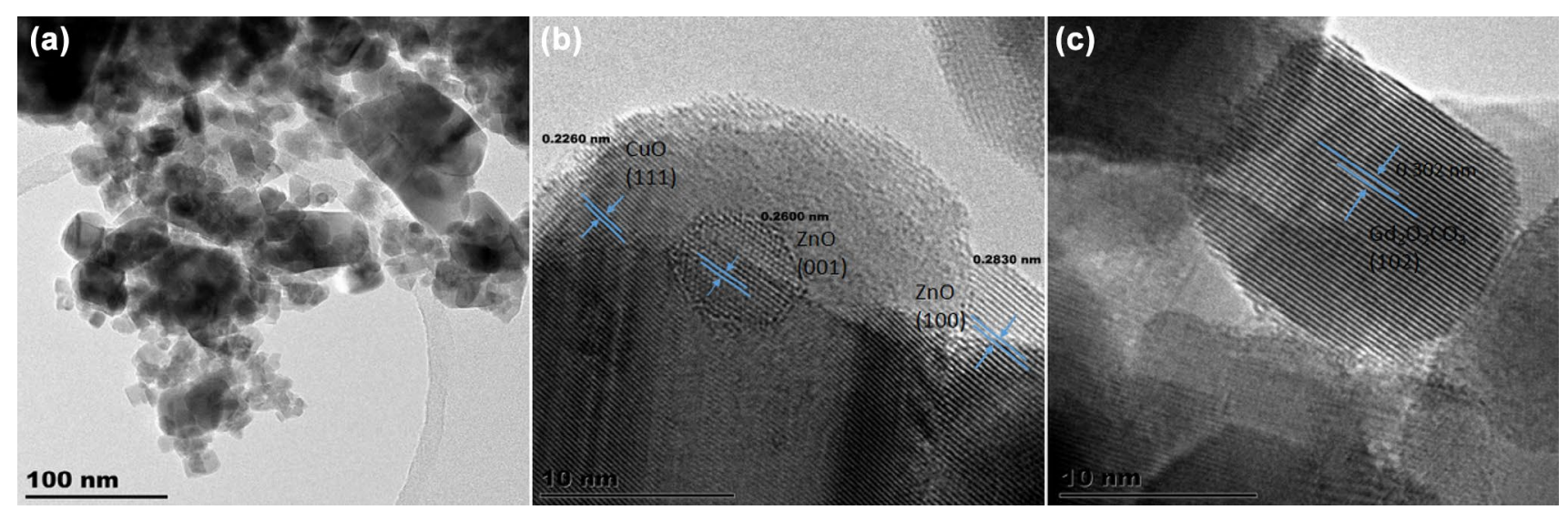

Fig. 6 Low magnification TEM image (a) and HRTEM image of $\mathrm{Gd}_{2} \mathrm{O}_{2} \mathrm{CO}_{3} \cdot \mathrm{ZnO} \cdot \mathrm{CuO} N \mathrm{NC}(\mathbf{b}-\mathbf{c})$

\section{SN Applied Sciences}




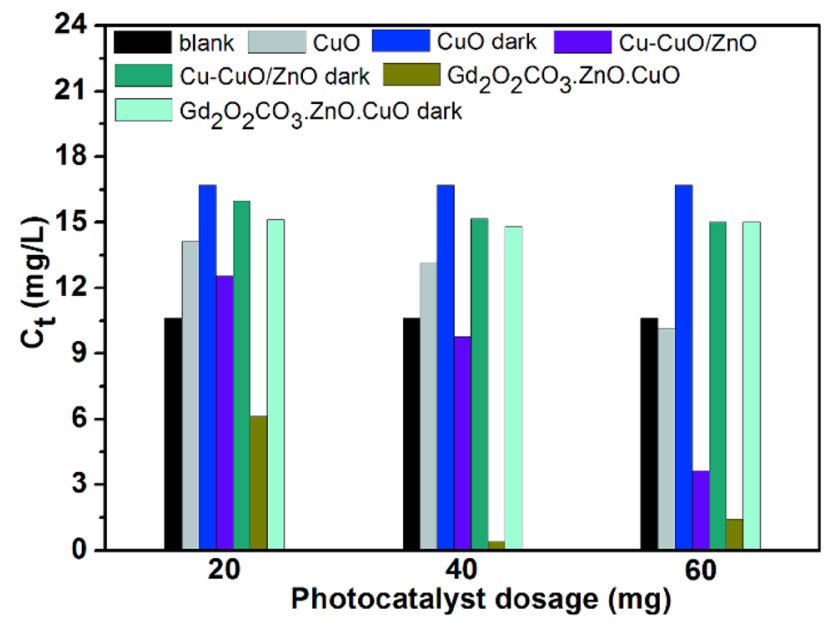

Fig. 7 Effect of catalyst dosage on the degradation of phenanthrene

were both $0.6 \mathrm{gL}^{-1}$, while that of the $\mathrm{Gd}_{2} \mathrm{O}_{2} \mathrm{CO}_{3} \cdot \mathrm{ZnO} \cdot \mathrm{CuO}$ $\mathrm{NC}$ was $0.4 \mathrm{gL}^{-1}$. The rate of photocatalytic degradation increased upon increasing the dosage of each photocatalyst prior to decreasing again at higher loading. For example, in the case of $\mathrm{Gd}_{2} \mathrm{O}_{2} \mathrm{CO}_{3} \cdot \mathrm{ZnO} \cdot \mathrm{CuO}$, a catalyst loading $>0.6 \mathrm{gL}^{-1}$ gave reduced degradation efficiencies, likely due to particle aggregation.

\subsubsection{Effect of illumination time}

The effect of illumination time was then investigated by measuring the photodegradation efficiency at $20 \mathrm{~min}$ intervals using the optimal catalyst loadings and a $20 \mathrm{ppm}$ phenanthrene solution $(100 \mathrm{~mL})$ at $\mathrm{pH} 4$ under visible light at room temperature. As shown in Fig. 8, the rate of phenanthrene degradation increased with time due to

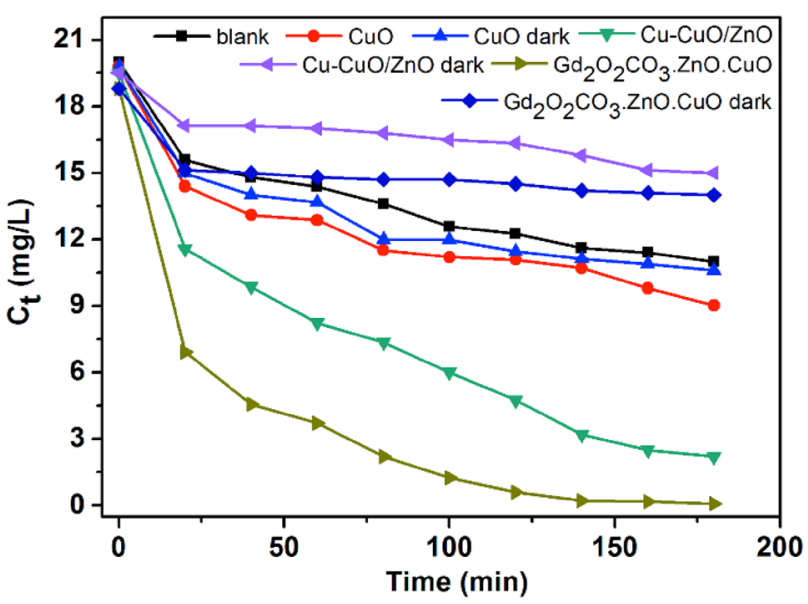

Fig. 8 Effect of time on the degradation of phenanthrene the adsorption of phenanthrene molecules on the catalyst surface and their subsequent degradation. However, in the absence of visible light or a catalyst, no significant degradation of phenanthrene was observed, thereby indicating that phenanthrene is relatively stable under the above mentioned conditions. These results confirm that both visible light and a photocatalyst are required for the effective degradation of phenanthrene. It was also found that the initial photodegradation rate was high due to the availability of numerous active catalytic sites. In addition, over the reaction time employed herein, the $\mathrm{CuO}$ $\mathrm{NPs}$, the $\mathrm{Cu}-\mathrm{CuO} / \mathrm{ZnO} \mathrm{NC}$, and the $\mathrm{Gd}_{2} \mathrm{O}_{2} \mathrm{CO}_{3} \cdot \mathrm{ZnO} \cdot \mathrm{CuO}$ $\mathrm{NC}$ contributed to reduce $8.88,17.74$, and $20 \mathrm{ppm}$ of the phenanthrene concentration, respectively, thereby indicating that the $\mathrm{Gd}_{2} \mathrm{O}_{2} \mathrm{CO}_{3} \cdot \mathrm{ZnO} \cdot \mathrm{CuO} \mathrm{NC}$ is the most efficient photocatalyst for phenanthrene removal in solution under the conditions employed herein. Indeed, when the $\mathrm{Gd}_{2} \mathrm{O}_{2} \mathrm{CO}_{3} \cdot \mathrm{ZnO} \cdot \mathrm{CuO} \mathrm{NC}$ was employed, $99.6 \%$ phenanthrene removal was achieved within $180 \mathrm{~min}$.

\subsubsection{Effect of oxidant addition}

Detection of the main active oxidative species in the removal of phenanthrene is necessary to determine the photocatalytic activity. Thus, the effect of $\mathrm{K}_{2} \mathrm{~S}_{2} \mathrm{O}_{8}$ and $\mathrm{Na}_{2} \mathrm{~S}_{2} \mathrm{O}_{8}$ on the photocatalytic degradation process was examined using an oxidant concentration of $2 \mathrm{mM}$ under otherwise equivalent conditions. As shown in Fig. 9, the addition of both oxidants to the reaction solution enhanced the rate of phenanthrene photocatalytic degradation under visible light. This can be attributed to the trapping of electrons by $\mathrm{Na}_{2} \mathrm{~S}_{2} \mathrm{O}_{8} / \mathrm{K}_{2} \mathrm{~S}_{2} \mathrm{O}_{8}$ minimizing the possibility of recombination of electron/hole pairs. Furthermore, the enhanced performance in the presence of oxidants could be accounted for by the production

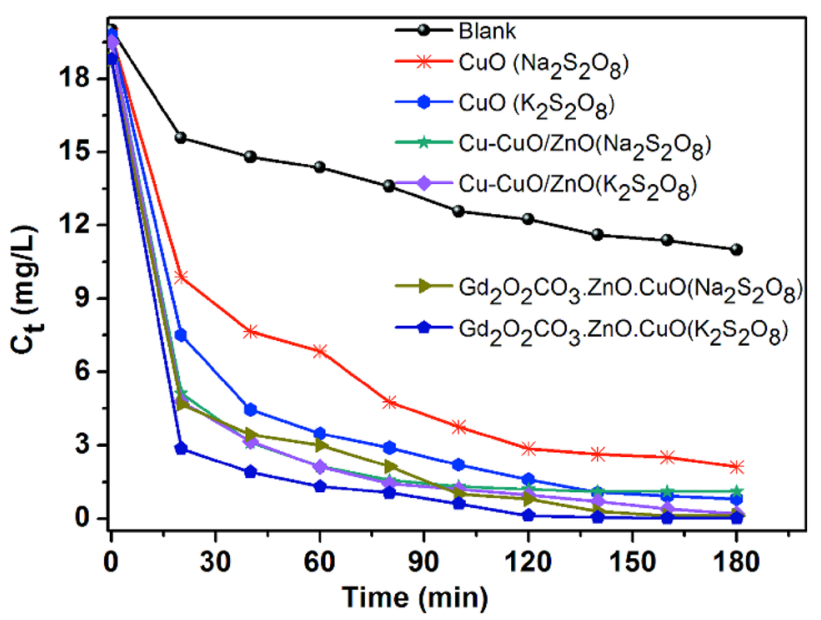

Fig. 9 Effect of oxidant addition on the degradation of phenanthrene 
of reactive sulfate radical anion $\left(\mathrm{SO}_{4}^{--}\right)$and hydroxyl radical $(\mathrm{OH})$. The rate of photodegradation was high in case $\mathrm{K}_{2} \mathrm{~S}_{2} \mathrm{O}_{8}$ due to fast dissociation and high radical availability $[40,41]$. The role of oxidants in acceleration of photodegradation of phenanthrene can be explained by the following reactions.

$\mathrm{S}_{2} \mathrm{O}_{8}^{2-}+\mathrm{e}^{-}(\mathrm{CB}) \rightarrow \mathrm{SO}_{4}^{--}+\mathrm{SO}_{4}^{2-}$

$\mathrm{SO}_{4}^{--}+\mathrm{e}^{-}(\mathrm{CB}) \rightarrow \mathrm{SO}_{4}^{2-}$

$\mathrm{SO}_{4}^{--}+\mathrm{H}_{2} \mathrm{O} \rightarrow \mathrm{SO}_{4}^{2-}+\mathrm{H}^{+}+\mathrm{OH}^{-}$

$\mathrm{SO}_{4}^{--}+$Phenanthrene $\rightarrow \mathrm{SO}_{4}^{2-}+$ Intermediates

$\mathrm{SO}_{4}^{--}+$Intermediates $\rightarrow \mathrm{CO}_{2}+\mathrm{H}_{2} \mathrm{O}+$ less harmful products

The thiosulfate ion $\left(\mathrm{S}_{2} \mathrm{O}_{8}{ }^{2-}\right)$ reacts with available electron from conduction band (CB) and produces highly active $\mathrm{SO}_{4}^{-} \cdot \mathrm{SO}_{4}^{--}$is a very strong oxidizing agent $\left(\mathrm{E}^{\circ}=2.6 \mathrm{eV}\right)$. Later, these radicals might react with water molecules and generate hydroxyl radicals. As such, these generated active radicals might participate in photodegradation of phenanthrene into less harmful products.

\subsubsection{Kinetic analysis}

The Langmuir-Hinshelwood kinetic model which describes the kinetics of the heterogeneous photocatalytic system, was used to determine the reaction rate constant $(k)$ for the photodegradation of phenanthrene, as outlined in the following Eqs. (2-4) [36]:

$\frac{\mathrm{dc}}{\mathrm{dt}}=\frac{k K_{\text {phenanthrene }} C_{0}}{1+K_{\text {phenanthrene }} C_{0}}$

$\ln \left(C_{0} / C_{t}\right)=k K_{\text {phenanthrene }} t$

$\ln \left(C_{0} / C_{t}\right)=K_{a p p} t$

where $K_{\text {phenanthrene }}$ represents the adsorption coefficient of phenanthrene on the photocatalyst (L. $\mathrm{mg}^{-1}$ ), while $K_{\text {app }}$ represents the calculated apparent rate constant $\left(\mathrm{min}^{-1}\right)$, and $t$ is the reaction time ( $\mathrm{min}$ ). This model is commonly employed for photodegradation processes when the initial substrate concentration is low. As shown in Fig. 10, plots of $\ln \left(C_{0} / C_{t}\right)$ versus $t$ gave a linear relationship, thereby indicating that the kinetics data fit well with pseudo first order kinetics. In addition, as shown in Fig. 11, a reaction rate constant $K_{\text {app }}$ of $0.003 \mathrm{~m}^{-1}$ was obtained for $\mathrm{CuO}$ under visible light, while the $\mathrm{Cu}-\mathrm{CuO} / \mathrm{ZnO}$ composite gave a $K_{\text {app }}$ value of $0.011 \mathrm{~m}^{-1}$. These results indicate that the photocatalytic degradation activity of $\mathrm{CuO}$ nanoparticles was extremely low under visible light, potentially due to its high recombination rate of photogenerated charge

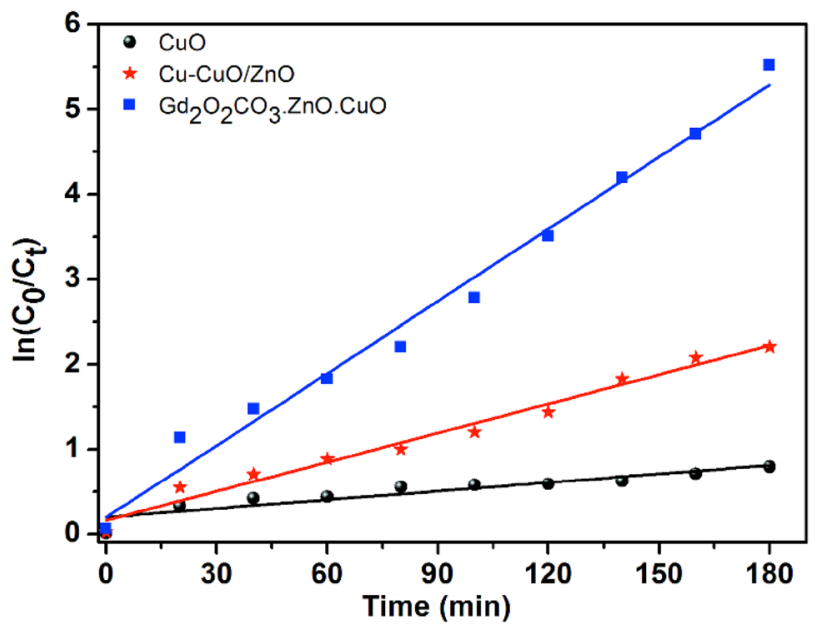

Fig. 10 Kinetic plot of phenanthrene degradation by $\mathrm{CuO}, \mathrm{Cu}-$ $\mathrm{CuO} / \mathrm{ZnO}$, and $\mathrm{Gd}_{2} \mathrm{O}_{2} \mathrm{CO}_{3} \cdot \mathrm{ZnO} \cdot \mathrm{CuO}$ photocatalysts

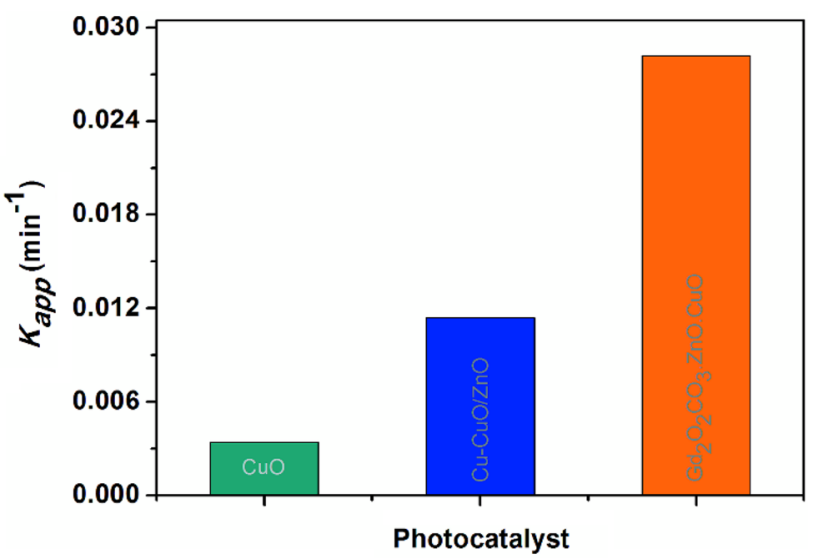

Fig. 11 Kinetic rate constants for $\mathrm{CuO} N \mathrm{NP}, \mathrm{Cu}-\mathrm{CuO} / \mathrm{ZnO} \mathrm{NC}$, and $\mathrm{Gd}_{2} \mathrm{O}_{2} \mathrm{CO}_{3} \cdot \mathrm{ZnO} \cdot \mathrm{CuO} \mathrm{NC}$ in the photocatalytic degradation of phenanthrene

carriers. It is therefore expected that the $\mathrm{Cu}-\mathrm{CuO} / \mathrm{ZnO}$ $\mathrm{NC}$ exhibited an improved photocatalytic activity due to the generation of reactive oxygen species (ROS) and distribution of the photogenerated charge carriers over the $\mathrm{Cu}$ and $\mathrm{ZnO}$ NPs, thereby delaying the recombination of electron-holes pairs. However, the $\mathrm{Gd}_{2} \mathrm{O}_{2} \mathrm{CO}_{3} \cdot \mathrm{ZnO} \cdot \mathrm{CuO} \mathrm{NC}$ was found to be the optimal photocatalyst for the degradation of phenanthrene in solution under visible light, with a reaction rate constant $K_{\text {app }}$ of $0.06 \mathrm{~m}^{-1}$ being calculated. Moreover, this photocatalyst gave almost $100 \%$ photodegradation of a $20 \mathrm{mg} / \mathrm{L}$ phenanthrene solution over $120 \mathrm{~min}$. The highest photocatalytic efficiency of $\mathrm{Gd}_{2} \mathrm{O}_{2} \mathrm{CO}_{3} \cdot \mathrm{ZnO} \cdot \mathrm{CuO} \mathrm{NC}$ can be ascribed to high light absorption, slow recombination rate and high surface area. The photocatalytic activities of the prepared materials therefore follow the trend: $\mathrm{CuO}(50.4 \%)<\mathrm{Cu}-\mathrm{CuO} / \mathrm{ZnO}$ 
$(89.0 \%)<\mathrm{Gd}_{2} \mathrm{O}_{2} \mathrm{CO}_{3} \cdot \mathrm{ZnO} \cdot \mathrm{CuO}(99.6 \%)$. The obtained trend of photocatalytic activities can also be supported by BET surface area observations.

The photocatalytic performance of a catalyst depends on the transport and recombination of photogenerated electron-hole pairs, in addition to the light harvesting properties of the photocatalyst, and the presence of sufficient active sites for adsorption of the organic substrate on the catalyst surface. It is therefore evident from the results presented above that multimetal oxide NCs demonstrate large optical absorbance and contain high numbers of active sites. Moreover, the most plausible mechanism for the photocatalytic degradation of phenanthrene using $\mathrm{Gd}_{2} \mathrm{O}_{2} \mathrm{CO}_{3} \cdot \mathrm{ZnO} \cdot \mathrm{CuO} \mathrm{NC}$ is proposed in Fig. 12 and can be explained using the following equations.

$$
\begin{aligned}
& \mathrm{h} v+\mathrm{Gd}_{2} \mathrm{O}_{2} \mathrm{CO}_{3} \rightarrow \mathrm{Gd}_{2} \mathrm{O}_{2} \mathrm{CO}_{3}\left(\mathrm{~h}_{\mathrm{VB}}^{+}+\mathrm{e}_{\mathrm{CB}}^{-}\right) \\
& \mathrm{h} v+\mathrm{CuO} / \mathrm{ZnO} \rightarrow \mathrm{CuO} / \mathrm{ZnO}\left(\mathrm{h}_{\mathrm{vB}}^{+}+\mathrm{e}_{\mathrm{CB}}^{-}\right) \\
& \mathrm{CuO} / \mathrm{ZnO}\left(\mathrm{h}_{\mathrm{vB}}^{+}+\mathrm{e}_{\mathrm{CB}}^{-}\right) \rightarrow \mathrm{CuO}\left(\mathrm{h}_{\mathrm{vB}}^{+}\right)+\mathrm{ZnO}\left(\mathrm{e}_{\mathrm{CB}}^{-}\right) \\
& \mathrm{ZnO}\left(\mathrm{e}_{\mathrm{CB}}^{-}\right)+\mathrm{O}_{2} \rightarrow \mathrm{O}_{2}^{-} \\
& \mathrm{CuO}\left(\mathrm{h}_{\mathrm{vB}}^{+}\right)+\mathrm{H}_{2} \mathrm{O} \rightarrow \mathrm{OH}^{+} \mathrm{H}^{+} \\
& \mathrm{O}_{2}^{-}+\mathrm{H}_{2} \mathrm{O} \rightarrow \mathrm{OH}+\mathrm{HO}^{-}+\mathrm{O}_{2} \\
& \mathrm{OH}+\text { Phenanthrene } \rightarrow \text { Degarded products }
\end{aligned}
$$

Upon irradiation of light, all metal oxides can be excited to produce the photoinduced electrons and holes. Due to establishment of force of electric field, the photogenerated electrons are shifted to conduction band (CB) of p-type CuO NPs to the CB of n-type $\mathrm{ZnO}$. This leads to efficient separation of the photo-generated charge carriers (electrons and holes) at the $\mathrm{CuO} / \mathrm{ZnO}$ heterojunction interface, resulting to lower recombination rate [42]. The produced charge carriers are moved to nanocomposite surface where the holes participate to convert water molecules to hydroxyl radicals $(\mathrm{OH})$ and electrons are used

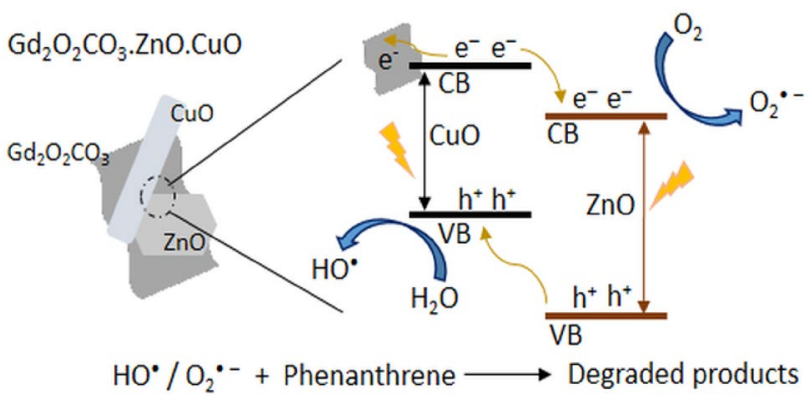

Fig. 12 Schematic illustration of plausible mechanism for photocatalytic degradation of phenanthrene using $\mathrm{Gd}_{2} \mathrm{O}_{2} \mathrm{CO}_{3} \cdot \mathrm{ZnO} \cdot \mathrm{CuO}$ NC by dissolved oxygen to form superoxide anion radicals $\left(\mathrm{O}_{2}^{-}\right)$. These reactive oxygen species ( $\left.\mathrm{ROS}-\mathrm{O}_{2}^{-}, \mathrm{OH}_{,} \mathrm{OH}^{-}\right)$ might facilitate the photodegradation of phenanthrene to generate less harmful degraded products $[11,36,43,44]$. The ROS can attack the reactive positions (i.e., the 9 and/ or 10 positions) of phenanthrene and disturb the electron arrangement of the phenanthrene aromatic rings, which results in the formation of intermediate products such as alcohol, ketone, and aldehyde derivatives [45]. These intermediate products can then be converted into stable and less harmful products, including carbon dioxide and water. Thus, the enhanced photocatalytic properties of the $\mathrm{Gd}_{2} \mathrm{O}_{2} \mathrm{CO}_{3} \cdot \mathrm{ZnO} \cdot \mathrm{CuO} \mathrm{NC}$ can possibly be attributed to reduced electron-hole recombination rates due to the photogenerated electrons from $\mathrm{CuO}$ being easily transported on the multidirectional $\mathrm{Gd}_{2} \mathrm{O}_{2} \mathrm{CO}_{3}$ and $\mathrm{ZnO}$ and high light absorption.

\section{Conclusion}

We herein reported the successful synthesis of multimetal $\mathrm{Gd}_{2} \mathrm{O}_{2} \mathrm{CO}_{3} \cdot \mathrm{ZnO} \cdot \mathrm{CuO}$ nanocomposite (NC) based photocatalyst via a simple co-precipitation method. Pure $\mathrm{CuO}$ nanoparticles (NPs) were synthesized via an environmentally friendly method based on the use of banana peel as structure-controlling agent. In addition, electron microscopies (i.e. SEM, TEM) and XRD study confirmed that the $\mathrm{Gd}_{2} \mathrm{O}_{2} \mathrm{CO}_{3} \cdot \mathrm{ZnO} \cdot \mathrm{CuO} \mathrm{NC}$ contained $\mathrm{ZnO}$ and $\mathrm{CuO}$ particles anchored onto the composite surface. In terms of the photocatalytic activities of the various prepared photocatalysts, the $\mathrm{Gd}_{2} \mathrm{O}_{2} \mathrm{CO}_{3} \cdot \mathrm{ZnO} \cdot \mathrm{CuO} \mathrm{NC}$ exhibited a superior photocatalytic activity in the degradation of phenanthrene, likely due to reduced electron-hole recombination rates and the production of large amount of reactive oxygen species. The developed multimetal oxides $\mathrm{Gd}_{2} \mathrm{O}_{2} \mathrm{CO}_{3} \cdot \mathrm{ZnO} \cdot \mathrm{CuO} \mathrm{NC}$ photocatalyst gave almost $100 \%$ photodegradation of a $20(\mathrm{mg} / \mathrm{L})$ phenanthrene solution over $180 \mathrm{~min}$. It was also observed that the degradation of phenanthrene by $\mathrm{Gd}_{2} \mathrm{O}_{2} \mathrm{CO}_{3} \cdot \mathrm{ZnO} \cdot \mathrm{CuO} \mathrm{NC}$ was adequately predicted by the Langmuir-Hinshelwood kinetic model. We therefore expect that the developed multimetal oxide $\mathrm{NCs}$ will be applicable for the treatment of other emerging pollutants to produce stable and less harmful products. Further studies will focus on this potential application, and on detailed mechanistic studies regarding the degradation of phenanthrene using the system described herein.

Acknowledgements The authors are grateful to the sponsor from the North-West University and the National Research Foundation (NRF, Grant 94152) in South Africa. Any opinion, findings and conclusions or recommendations expressed in this material are those of the authors and therefore the NRF does not accept any liability 
in regard thereto. The authors appreciate the assistance of Mr Nico Lemmer from the North-West University.

\section{Compliance with ethical standards}

Conflict of interest The authors declare that they have no conflict of interest.

\section{References}

1. Lamichhane S, Bal Krishna KC, Sarukkalige R (2016) Polycyclic aromatic hydrocarbons (PAHs) removal by sorption: a review. Chemosphere 148:336-353

2. Fosso-Kankeu E, Mittal H, Waanders F, Ray SS (2017) Thermodynamic properties and adsorption behaviour of hydrogel nanocomposites for cadmium removal from mine effluents. J Ind Eng Chem 48:151-161

3. Manyatshe A, Fosso-Kankeu E, van der Berg D, Lemmer N, Waanders $\mathrm{F}$, Tutu $\mathrm{H}$ (2018) Metal speciation in the rivers around Potchefstroom based on seasonality. Water Environ Res 90(1):84-95

4. Fosso-Kankeu E (2018) Synthesized af-PFCl and GG-g-P(AN)/ TEOS hydrogel composite used in hybridized technique applied for AMD treatment. J Phys Chem Earth 105:170-176

5. Yang $Y$, Hildebrand $F(2006)$ Phenanthrene degradation in subcritical water. Anal Chim Acta 555:364-369

6. Farhadian M, Sangpour P, Hosseinzadeh G (2016) Preparation and photocatalytic activity of $\mathrm{WO}_{3}-\mathrm{MWCNT}$ nanocomposite for degradation of naphthalene under visible light irradiation. RSC Adv 6:39063-39073

7. Tithof PK, Elgayyar M, Cho Y, Guan W, Fisher AB, Peters-Golden M (2002) Polycyclic aromatic hydrocarbons present in cigarette smoke cause endothelial cell apoptosis by a phospholipase A2-dependent mechanism. FASEB J 16:1463-1464

8. Prosser CM, Unger MA, Vogelbein WK (2011) Multistressor interactions in the zebrafish (Danio rerio): concurrent phenanthrene exposure and Mycobacterium marinum infection. Aquat Toxicol 102:177-185

9. Konstantinou IK, Albanis TA (2004) $\mathrm{TiO}_{2}$-assisted photocatalytic degradation of azo dyes in aqueous solution: kinetic and mechanistic investigations: a review. Appl Catal B 49:1-14

10. Zhang C, Yin L, Zhang L, Qi Y, Lun N (2012) Preparation and photocatalytic activity of hollow $\mathrm{ZnO}$ and $\mathrm{ZnO}-\mathrm{CuO}$ composite spheres. Mater Lett 67:303-307

11. Kumar N, Mittal H, Reddy L, Nair P, Ngila JC, Parashar V (2015) Morphogenesis of $\mathrm{ZnO}$ nanostructures: role of acetate $\left(\mathrm{CH}_{3} \mathrm{COO}^{-}\right)$and nitrate $\left(\mathrm{NO}_{3}{ }^{-}\right)$ligand donor from zinc salt precursors in synthesis and morphology dependent photo-catalytic properties. RSC Adv 5:38801-38809

12. Kumar N, Mittal H, Parashar V, Ray SS, Ngila JC (2016) Efficient removal of rhodamine $6 \mathrm{G}$ dye from aqueous solution using nickel sulphide incorporated polyacrylamide grafted gum karaya bionanocomposite hydrogel. RSC Adv 6:21929-21939

13. Schoeman J, Steyn A (2003) Nitrate removal with reverse osmosis in a rural area in South Africa. Desalination 155:15-26

14. Fakhru'l-Razi A, Pendashteh A, Abdullah LC, Biak DRA, Madaeni SS, Abidin ZZ (2009) Review of technologies for oil and gas produced water treatment. J Hazard Mater 170:530-551

15. Kumar N, Reddy L, Ngila JC, Parashar V (2017) Controlled synthesis of microsheets of $\mathrm{ZnAl}$ layered double hydroxides hexagonal nanoplates for efficient removal of $\mathrm{Cr}(\mathrm{VI})$ ions and anionic dye from water. J Environ Chem Eng 5:1718-1731
16. Felix A, Amenaghawon A, Mededode A (2014) Heterogeneous photocatalytic degradation of naphthalene using periwinkle shell ash: effect of operating variables, kinetic and isotherm study. S Afr J Chem Eng 19:31-45

17. Chakrabarti S, Dutta BK (2004) Photocatalytic degradation of model textile dyes in wastewater using $\mathrm{ZnO}$ as semiconductor catalyst. J Hazard Mater 112:269-278

18. Ahmad M, Ahmed E, Hong Z, Khalid N, Ahmed W, Elhissi A (2013) Graphene-Ag/ZnO nanocomposites as high performance photocatalysts under visible light irradiation. J Alloys Compd 577:717-727

19. Attia YA (2016) Ag/ZnO/graphene-tert-butyldimethylsilyl chloride hybrid nanocomposite as highly efficient catalyst for hydrogen production. Mater Express 6:211-219

20. Zaoui A, Ferhat M, Ahuja R (2009) Magnetic properties of (ZnO)1/(CuO)1(001) superlattice. Appl Phys Lett 94:102102

21. Saravanan R, Karthikeyan S, Gupta V, Sekaran G, Narayanan V, Stephen A (2013) Enhanced photocatalytic activity of $\mathrm{ZnO} /$ $\mathrm{CuO}$ nanocomposite for the degradation of textile dye on visible light illumination. Mater Sci Eng C 33:91-98

22. Zhou K, Wang R, Xu B, Li Y (2006) Synthesis, characterization and catalytic properties of $\mathrm{CuO}$ nanocrystals with various shapes. Nanotechnology 17:3939-3943

23. Verma S, Kumar N, Jain SL (2012) Copper (II) trans-bis(glycinato): an efficient heterogeneous catalyst for cross coupling of phenols with aryl halides. Tetrahedron Lett 53:4665-4668

24. Jiang Y, He X, Zhang W, Li X, Guo N, Zhao Y, Xu G, Li W (2015) Metallic copper wire: a simple, clear and reusable catalyst for the CuAAC reaction in supercritical carbon dioxide. RSC Adv 5:73340-73345

25. Yu J, Zhuang S, Xu X, Zhu W, Feng B, Hu J (2015) Photogenerated electron reservoir in hetero- $\mathrm{p}-\mathrm{n} \mathrm{CuO}-\mathrm{ZnO}$ nanocomposite device for visible-light-driven photocatalytic reduction of aqueous $\mathrm{Cr}(\mathrm{VI})$. J Mater Chem A 3:1199-1207

26. Wei S, Chen $Y, M a Y$, Shao Z (2010) Fabrication of CuO/ZnO composite films with cathodic co-electrodeposition and their photocatalytic performance. J Mol Catal A Chem 331:112-116

27. Chang T, Li Z, Yun G, Jia Y, Yang H (2013) Enhanced photocatalytic activity of $\mathrm{ZnO} / \mathrm{CuO}$ nanocomposites synthesized by hydrothermal method. Nano-Micro Lett 5:163-168

28. Zhang N, Chen D, Niu F, Wang S, Qin L, Huang Y (2016) Enhanced visible light photocatalytic activity of $\mathrm{Gd}$ doped $\mathrm{BiFeO}_{3}$ nanoparticles and mechanism insight. Sci Rep 6:26467

29. Barrera A, Tzompantzi F, Campa-Molina J, Casillas JE, PerezHernandez R, Ulloa-Godinez S, Velasquez C, Arenas-Alatorre J (2018) Photocatalytic activity of $\mathrm{Ag} / \mathrm{Al}_{2} \mathrm{O}_{3}-\mathrm{Gd}_{2} \mathrm{O}_{3}$ photocatalysts prepared by the sol-gel method in the degradation of 4-chlorophenol. RSC Adv 8:3108-3119

30. Subhan MA, Ahmed T, Awal MR, Mansur A, Fahim M (2014) Synthesis, structure and excitation wavelength dependent PL properties of novel nanocomposite $\mathrm{La}_{2} \mathrm{O}_{2} \mathrm{CO}_{3} \cdot \mathrm{CuO} \cdot \mathrm{ZnO}$. Spectrochim Acta A 132:550-554

31. Meghana S, Kabra P, Chakraborty S, Padmavathy N (2015) Understanding the pathway of antibacterial activity of copper oxide nanoparticles. RSC Adv 5:12293-12299

32. Rittermeier A, Miao S, Schröter MK et al (2009) The formation of colloidal copper nanoparticles stabilized by zinc stearate: onepot single-step synthesis and characterization of the core-shell particles. Phys Chem Chem Phys 11:8358-8366

33. Li IF, Su CH, Sheu HS, Chiu HC, Lo YW, Lin WT, Chen JH, Yeh CS (2008) $\mathrm{Gd}_{2} \mathrm{O}\left(\mathrm{CO}_{3}\right) \cdot 2 \mathrm{H}_{2} \mathrm{O}$ Particles and the corresponding $\mathrm{Gd}_{2} \mathrm{O}_{3}$ : synthesis and applications of magnetic resonance contrast agents and template particles for hollow spheres and hybrid composites. Adv Funct Mater 18:766-776 
34. Moser S, Müller T, Oberhuber M, Kräutler B (2009) Chlorophyll catabolites-chemical and structural footprints of a fascinating biological phenomenon. Eur J Org Chem 2009:21-31

35. Rodriguez-Blanco JD, Shaw S, Benning LG (2001) The kinetics and mechanisms of amorphous calcium carbonate (ACC) crystallization to calcite, via vaterite. Nanoscale 3:265-271

36. Kumar N, Ray SS, Ngila JC (2017) lonic liquid-assisted synthesis of $\mathrm{Ag} / \mathrm{Ag}_{2} \mathrm{Te}$ nanocrystals via a hydrothermal route for enhanced photocatalytic performance. New J Chem 41:14618-14626

37. Kumar N, George BPA, Abrahamse H, Parashar V, Ray SS, Ngila JC (2017) A novel approach to low temperature synthesis of cubic $\mathrm{HfO}_{2}$ nanostructures and their cytotoxicity. Sci Rep 7:9351

38. Daneshvar N, Salari D, Khataee A (2004) Photocatalytic degradation of azo dye acid red 14 in water on $\mathrm{ZnO}$ as an alternative catalyst to $\mathrm{TiO}_{2}$. J Photochem Photobiol, A 162:317-322

39. Wang CC, Lee CK, Lyu MD, Juang LC (2008) Photocatalytic degradation of $\mathrm{Cl}$ Basic Violet 10 using $\mathrm{TiO}_{2}$ catalysts supported by $\mathrm{Y}$ zeolite: an investigation of the effects of operational parameters. Dyes Pigment 76:817-824

40. Xu X, Ye Q, Tang T, Wang D (2008) Hg0 oxidative absorption by $\mathrm{K}_{2} \mathrm{~S}_{2} \mathrm{O}_{8}$ solution catalyzed by $\mathrm{Ag}^{+}$and $\mathrm{Cu}^{2+}$. J Hazard Mater 158:410-416
41. Shanthi M, Kuzhalosai V (2012) Photocatalytic degradation of an azo dye, Acid Red 27, in aqueous solution using nano $\mathrm{ZnO}$. Indian J Chem 51:428-434

42. Umukoro EH, Kumar N, Ngila JC, Arotiba OA (2018) Expanded graphite supported $\mathrm{p}-\mathrm{n} \mathrm{MoS}_{2}-\mathrm{SnO}_{2}$ heterojunction nanocomposite electrode for enhanced photo-electrocatalytic degradation of a pharmaceutical pollutant. J Electroanal Chem 827:193-203

43. Liu W, Zhao X, Borthwick AGL, Wang Y, Ni J (2015) Dual-enhanced photocatalytic activity of Fe-deposited titanate nanotubes used for simultaneous removal of As(III) and As(V). ACS Appl Mater Interfaces 7:19726-19735

44. Ama OM, Kumar N, Adams FV, Ray SS (2018) Efficient and costeffective photoelectrochemical degradation of dyes in wastewater over an exfoliated graphite- $\mathrm{MoO}_{3}$ nanocomposite electrode. Electrocatalysis 9:623-631

45. Fua J, Kyzasc GZ, Caia Z, Deliyannid EA, Liub W, Zhaob D (2018) Photocatalytic degradation of phenanthrene by graphite oxide$\mathrm{TiO}_{2}-\mathrm{Sr}(\mathrm{OH})_{2} / \mathrm{SrCO}_{3}$ nanocomposite under solar irradiation: effects of water quality parameters and predictive modelling. Chem Eng J 335:290-300 